\title{
Educando com design de animação: uma metodologia de ensino e aprendizagem
}

\author{
Educating with animation design: a methodology of teaching and learning \\ Márcio C. Barbosa, Pedro H. dos Santos, Manoel G. Alcoforado, Anna R. Sartore
}

design, animação, educação, metodologia, tecnologia

\begin{abstract}
As novas tecnologias digitais têm trazido mudanças de paradigma na sociedade com relação aos processos de aprendizagem. Todavia, a escola, sobretudo na sua vertente pública e gratuita, se mantém distante desse processo de transformação, tanto pelo desconhecimento das possibilidades propiciadas por esses novos recursos, quanto pela dificuldade de adaptação às suas propostas metodológicas. Acreditamos que o Design de Animação pode alterar essa realidade ao adequar os conteúdos de ensino a recursos disponibilizados pelas novas plataformas digitais. Logo, o presente artigo apresentará uma metodologia que possa auxiliar os professores na aplicação do Design de Animação em sala de aula, visando favorecer a motivação que precisa estar presente no processo de ensino e aprendizado.
\end{abstract}

design, animation, education, methodology, technology

The new digital technologies have brought paradigm shifts in society with respect to the processes of learning. However, the school, especially in the public dimension and free, if keeps far of this transformation process, both by the unfamiliarity of the possibilities offered by these new resources, as by difficulty of adaptation to their methodological proposals. We believe that Animation Design can change this reality to adapt the contents of the teaching resources provided by new digital platforms. Therefore, this article will present a methodology that can assist teachers in application in the Animation Design in the classroom in order to facilitate motivation that must be present in the process of teaching and learning.

\section{Introdução}

No atual estágio de desenvolvimento do mundo contemporâneo, as tecnologias digitais vêm se apresentando como uma emergente ferramenta que, cada vez mais, ganha destaque na vida da sociedade, afetando de forma significativa as tarefas cotidianas. O uso das TDICs - Tecnologias Digitais de Informação e Comunicação - é cada vez mais corriqueiro, tornando, hoje, saberes sobre elas indispensáveis. Atividades intermediadas pelas novas tecnologias interferem e potencializam, de forma relevante, os processos produtivos, as relações de trabalho e a comunicação dos indivíduos.

Embora os benefícios decorrentes do uso das TDICs sejam indiscutíveis, uma grande parcela da sociedade encontra-se marginalizada do uso destes recursos tecnológicos. Esta segregação acaba por ocasionar cidadãos infoexcluídos, ou seja, que não compartilham das oportunidades oferecidas pelo contato com a informação digital. Aras (2004) defende que a impossibilidade de utilização de recursos como o computador e a internet traz privações para algumas comunidades de obterem maiores conhecimentos e troca de informações, o que as enriqueceria social, cultural e economicamente.

Nesse contexto, um núcleo específico da sociedade se apresenta como instrumento capaz de conduzir a população ao contato efetivo com as TIDCs: a escola. Dessa forma, é fundamental esta entidade, na figura de seu corpo gestor e docente, estar atenta às transformações, difundindo na sala de aula o saber necessário à convivência com as novas demandas suscitadas pela globalização. Assim, faz-se necessário introduzir e fazer uso real das tecnologias digitais neste ambiente.

Sabe-se que o Governo arca atualmente com a aplicação de políticas públicas que intentam promover no cotidiano da escola e dos professores a interação com estas tecnologias. $O$ Programa Nacional de Tecnologia Educacional - PROINFO - tem levado laboratórios de informática e respectiva formação docente, às escolas públicas, na intenção de promover a utilização das 
TIDCs em sala de aula. Dados do Ministério da Educação apontam que, em 2006, cerca de 14 mil escolas já haviam sido contempladas com o programa.

No contexto local, a Secretaria de Educação do estado de Pernambuco tem investido na distribuição de computadores portáteis a professores. Em 2008, o programa realizou a entrega de cerca de 56 mil equipamentos à profissionais da educação e técnicos educacionais da rede estadual de ensino. Em uma segunda edição do programa, houve um investimento de aproximadamente 5 milhões nesta ação. O esforço mais recente, neste sentido, realizado no segundo semestre de 2012, diz respeito à entrega de 170 mil tablets-PC aos alunos da rede estadual de ensino.

Hoje, percebe-se, portanto, que as dificuldades de uso das TIDCs não residem mais na falta de computadores na Escola, mas sim nas dificuldades encontradas pelos professores em adaptar os conteúdos trabalhados em sala à estes potenciais instrumentos de aprendizagem. Sobre esta questão, Alcoforado e Padilha (2010: 2713) afirmam que "mesmo com a introdução crescente das TICS nas escolas [...] os professores ainda possuem muitas dificuldades na inclusão destes em seus planejamentos como recursos para definição de melhores estratégias de aprendizagem para seus alunos".

Uma alternativa pertinente para a solução desta problemática se resume na elaboração de estratégias que incentivem a construção de uma conexão palpável entre estas tecnologias e os conteúdos vivenciados no dia a dia escolar. Desta forma, crê-se que o Design de Animação é capaz de atender a estas expectativas, dando possibilidades concretas de inserção das novas tecnologias na escola.

Dessa maneira, o presente artigo visa apresentar os resultados da aplicação da metodologia Educando com Animação (elaborada em estudos anteriores), com professores e alunos de Escolas da rede municipal da cidade de Caruaru-PE, dentro do Programa de Educação Tutorial, denominado PET Infoinclusão: demanda da cultura, direito de todos, financiado pela CAPES. O projeto intenta fazer uso de técnicas do Design de Animação em sala de aula, incorporando-as aos conteúdos trabalhados pelos docentes, com vistas a promover o contato efetivo das TIDCs no ambiente de ensino e fomentar o interesse dos alunos pelos conteúdos vivenciados, fazendo deles sujeitos atuantes na construção do próprio conhecimento e, consequentemente, favorecendo o aprendizado.

\section{As TIDCs na escola}

Nos últimos anos, as constantes transformações acarretadas pelo desenvolvimento de novas tecnologias digitais, trouxeram significativas mudanças nos mais diversos campos da sociedade. A popularização do uso destas tecnologias protagonizou o que hoje é chamado de Revolução Digital. Lévy (1999: 28) afirma que "aquilo que identificamos [...] como "novas tecnologias" recobre na verdade a atividade multiforme de grupos humanos, um devir coletivo complexo que se cristaliza, sobretudo em volta de objetos materiais e programas de computador e de dispositivos de computador".

\section{Buzato (2001: 01), revela que:}

"as novas tecnologias da informação e da comunicação [...] estão relacionadas à produção de "desconectados" ou "excluídos", mas também às novas possibilidades de interagir, colaborar, representar, expressar identidades e pesquisar que há bem pouco tempo só existiam para pequenas elites culturais, acadêmicas e econômicas".

Percebe-se, hoje, uma preocupação por parte dos governantes em levar a população ao contato com as TIDCs. Na cidade de Caruaru-PE, essa realidade não é diferente, diversos programas têm sido implementados no município com o intuito de levar a informática e seus benefícios à realidade dos cidadãos. A exemplo disto, desde 2010, a Prefeitura Municipal de Caruaru tem desenvolvido o projeto Cidade Conectada, que transmite sinal de internet wi-fi para grande parte da cidade. A iniciativa tem permitido a moradores próximos de escolas municipais, de onde o sinal é transmitido, ter acesso gratuito e ilimitado à rede mundial de computadores.

No âmbito escolar, outras iniciativas públicas somam-se a esta e tentam conduzir alunos e professores ao acesso das novas linguagens midiáticas que predominam em nossos dias. Programas como o TV Escola, Banda Larga na Escola, Um Computador por Aluno e o próprio 
PROINFO, já citado anteriormente, tem tentado modernizar os paradigmas da educação brasileira. Logo, constata-se que a escola também tem sido foco intenso de investimentos em ações que promovem o contato com as novas tecnologias. Filatro (2007: 29) revela que:

"o papel do aluno, do professor, da avaliação e até a própria definição do que é saber estão sendo repensados à medida que computadores e redes eletrônicas invadem os espaços de aprendizagem tradicionais, ofertando inovações de imagem, som, movimento, hipertextualidade, virtualidade e realidade virtual".

Considerando, ainda, o percurso das ações de inserção das novas tecnologias na escola, percebe-se que a preocupação do governo em introduzir informática na educação não é recente. O primeiro projeto oficial instituído, intitulado de EDUCOM - Projeto Brasileiro de Informática na Educação -, teve seu início em 1983, numa parceria ente o MEC, CNPq e a Secretaria de Informática da Presidência da República. O programa visou desenvolver experimentos sobre as consequências do uso da informática nos processos de ensino e aprendizagem.

Alguns outros planos foram aplicados e tiveram uma significativa importância na busca pela inclusão digital nos ambientes de ensino. A seguir, apresentaremos uma sequência dos principais programas, de ordem nacional, aplicados com esta finalidade (Figura 01).

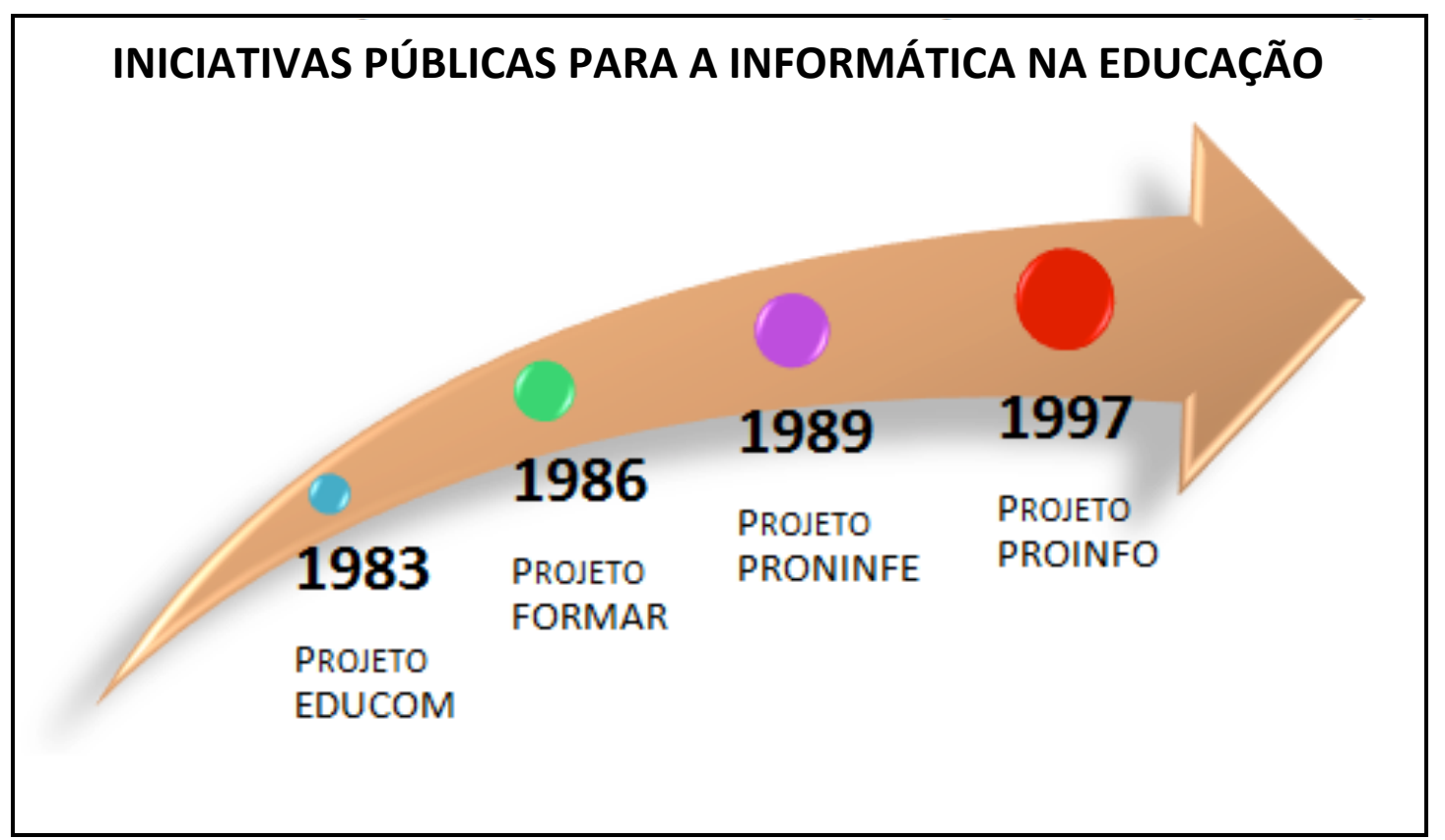

Mais recentemente o Ministério da Educação, através do Centro de Experimentação em Tecnologia Educacional (CETE), desenvolveu um sistema operacional livre, com o intuito de compor os laboratórios de informática das escolas públicas brasileiras. O Linux Educacional é baseado em uma distribuição GNU/Linux Kubuntu e se propõe a facilitar o uso pedagógico das ferramentas digitais, já que o sistema vem equipado com softwares direcionados a práticas educativas.

Diante dos dados expostos, percebe-se que a democratização das novas tecnologias digitais na escola brasileira é algo concreto. Porém, verifica-se que, em grande parte dos casos, esses recursos não são devidamente utilizados pelos docentes como instrumentos para potencializar o aprendizado.

\section{A animação como facilitador}

O ambiente escolar, em sua essência, é configurado com a finalidade de promover a aprendizagem. Muitas vezes, os métodos utilizados em sala de aula discordam desta afirmação e 
acabam por desestimular os discentes a buscarem um maior interesse pelos conteúdos trabalhados.

A prática do ensino é, por muitas vezes, realizada de forma autoritária, na qual o professor se coloca não como incentivador de construção do conhecimento, mas como detentor exclusivo deste. Freire (2005: 22) defende que "[...] ensinar não é transferir conhecimento, mas criar as possibilidades para a sua produção ou a sua construção", levando a crer que o ambiente ideal de ensino é aquele onde o conhecimento é edificado de forma participativa entre todos os que compõem uma sala de aula. O professor, portanto, carrega a função de mediador no processo de aprendizagem dos discentes.

Os equipamentos tecnológicos presentes nas escolas, entretanto, ainda não são direcionados pelos professores às práticas pedagógicas reais, sendo feito, muitas vezes, um uso meramente técnico destes. É necessário, portando, atribuir significados educacionais às TDICs, oferecendo aos professores possibilidades de levar os alunos a fazerem uso destes recursos, não como um passatempo, mas como um instrumento que auxilie na construção do saber.

Atentando a esta problemática, percebe-se que o Design de Animação apresenta-se como uma alternativa para alterar esta realidade, funcionando como um recurso mediador que interliga os equipamentos tecnológicos à aprendizagem dos alunos, conferindo, a estes, motivação pela busca da assimilação dos conteúdos trabalhados em aula, fazendo deles sujeitos atuantes da construção do próprio conhecimento. Para tanto, nos prendemos ao fato de que, ao passo em que a animação vai sendo gerada, os alunos têm a necessidade de se apropriarem dos conteúdos, já que eles serão necessários para fundamentar e dar sentido ao produto final. Logo, neste processo, é nítida a constatação de que de forma natural, haverá uma absorção destes assuntos, o que implicará em uma aprendizagem agradável e eficiente.

Desta forma, os alunos deixam a condição passiva na sala de aula, tornando-se produtores de conteúdo. As possibilidades de compartilhamento propiciadas pelas próprias TIDCs trazem ainda condições de criação de uma rede de socialização dos saberes incorporados aos materiais produzidos. Todo este processo leva a escola a uma aproximação das linguagens midiáticas já pertencentes ao cotidiano dos alunos. Alcoforado e Padilha (2010: 2714) acrescentam que:

[...] é importante lembrar que vivemos numa sociedade midiática. Utilizar recursos didáticos-tecnológicos na sala de aula não é somente aproximar a realidade do cotidiano do aluno às atividades da escola, mas é, principalmente, educar as crianças e jovens para o uso consciente da mídia".

A modificação dos métodos de aprendizagem, proporcionada pelas técnicas de animação, traz à sala de aula uma forma inovadora de ensino e aprendizagem, que, por sua vez, foge àquilo que normalmente é tratado na escola. Estas mudanças promovem uma importante e necessária aproximação dos envolvidos às TIDCs, que, durante as etapas de composição do filme animado, têm experiências que fazem uso direto das ferramentas disponibilizadas pelas tecnologias digitais, o que, fatalmente, condiciona-os ao contato com estas, favorecendo a inclusão digital (Figuras 02 e 03).

Figura 02 e 03: (à esq.) Aluno fazendo animação em flipbook em escola do município de Caruaru-PE e (à dir.) professor fazendo animação sobre história e geografia no treinamento realizado na UFPE. 

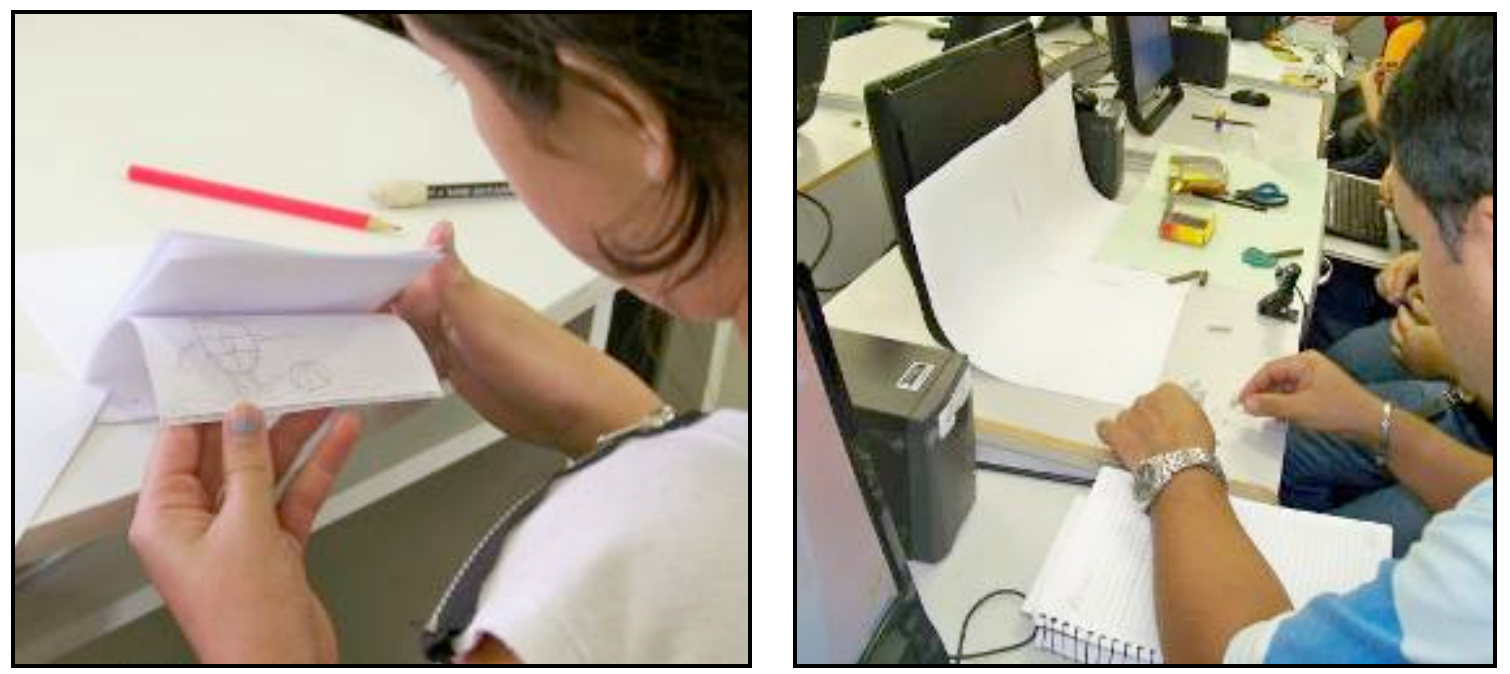

\section{Técnicas de construção de animação}

A animação faz referência basicamente ao processo artístico manual ou computacional de criar a ilusão de movimento contínuo através de imagens que, isoladamente são estáticas, mas quando sequenciadas de forma veloz proporcionam essa sensação de movimento ao observador. Para Andrade (2007:15), animação é o "gênero cinematográfico no qual se dá a ilusão de vida a imagens estáticas a partir da movimentação artificial num processo quadro-a-quadro, pela sobreposição destas em relação ao tempo".

A produção de uma animação pode ser realizada através do uso de diferenciadas técnicas, cada uma, por sua vez, possui diferentes níveis de complexidade e geram resultados estéticos distintos. Atualmente, é possível identificar uma variedade de técnicas de animação, das quais se destacam a animação tradicional, o stopmotion e a animação 3D.

Através de levantamentos feitos nos laboratórios de informática das escolas de Caruaru-PE, foi realizada uma sondagem dos equipamentos disponíveis. Esta verificação permitiu, em um primeiro momento, compreender a realidade tecnológica dessas escolas e, posteriormente, adequar a metodologia e técnicas de animação a serem usadas de forma a tornar viável o desenvolvimento do projeto.

A escolha das técnicas de animação levou em consideração, além da viabilidade tecnológica das escolas, a faixa etária das crianças, que nesse caso tinham entre 10 e 14 anos, cursando as $6^{\mathrm{a}}, 7^{\mathrm{a}}$ e $8^{\mathrm{a}}$ séries do ensino fundamental. As técnicas de animação escolhidas deveriam ser simples e práticas, para que não houvesse a necessidade de uma capacitação prolongada. Nesse sentido, as técnicas escolhidas foram: a Animação Tradicional e o Stopmotion. A seguir apresentaremos as técnicas indicadas para o trabalho em escolas.

\section{Animação Tradicional ou 2D}

Esta técnica se relaciona ao desenvolvimento manual de cada um dos quadros que compõem o filme de animação, onde os desenhos, em geral, são feitos com o auxílio de lápis e papel. Quando postos em sequência, as ilustrações passam a dar ideia de movimento (Figura 04).

Figura 04: Sequencia de desenhos de uma animação 2D abordando o crescimento de uma planta.

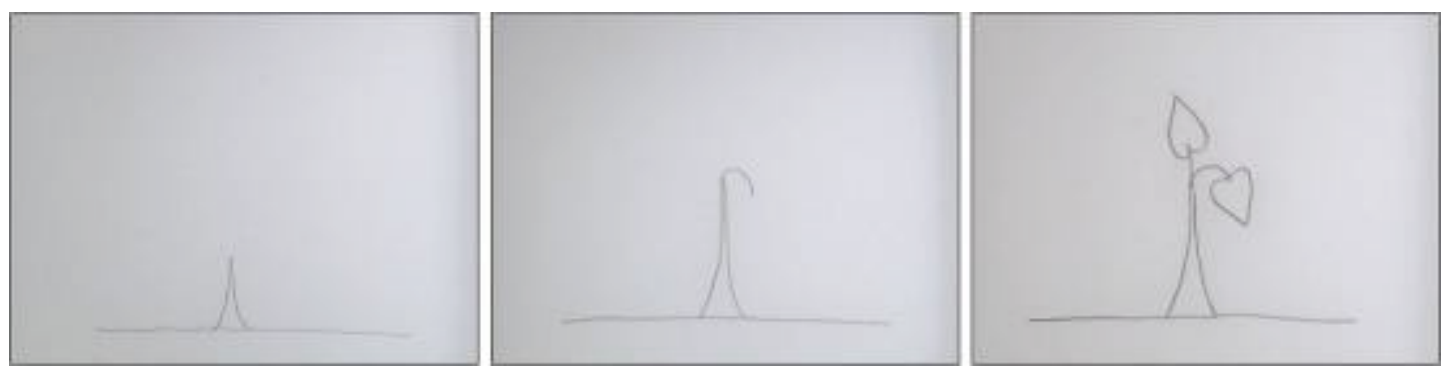


Márcio C. Barbosa, Pedro H. dos Santos, Manoel G. Alcoforado, Anna R. Sartore | Educando com design de animação: uma metodologia de ensino e aprendizagem

\section{Animação Stop-motion}

Diz respeito à captura da variação de movimentos de objetos ou pessoas. Esses são fotografados de forma sequencial a fim de gerar um vídeo contínuo, ou seja, uma animação. Uma das características típicas dessa técnica de animação trata-se do fato de se obter uma quebra de movimento durante a visualização da animação que atribui a essa técnica um diferencial interessante.

Dentre as variações desse tipo de animação, podemos destacar:

\section{Stop-motion com massinha}

A técnica compreende a captura de movimentos de personagens moldados com massa de modelar (Figura 05). Nesses, é possível incorporar estruturas de arame para facilitar a execução dos movimentos.

Figura 05: Animação com massa de modelar sobre a fotossíntese.

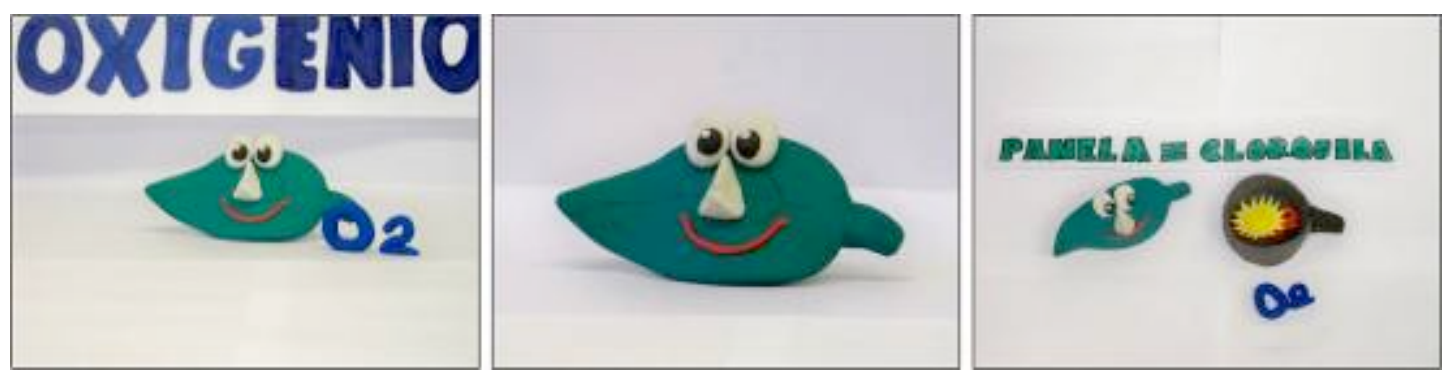

Stop-motion com objetos

Nesta técnica, a animação é realizada com o uso de objetos variados, que constituem os personagens da produção (Figura 06).

Figura 06: Animação com objetos sobre higiene bucal.
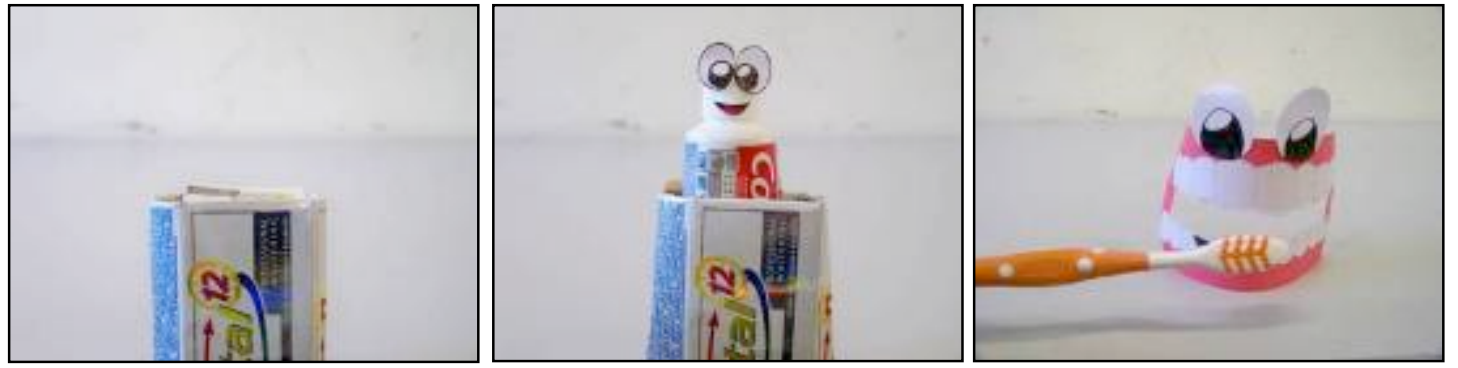

\section{Stop-motion com recortes}

A animação faz uso de personagens feitos de papeis diversos, compostos por articulações usadas na execução dos movimentos (Figura 07).

Figura 07: Animação com recortes sobre cidadania. 

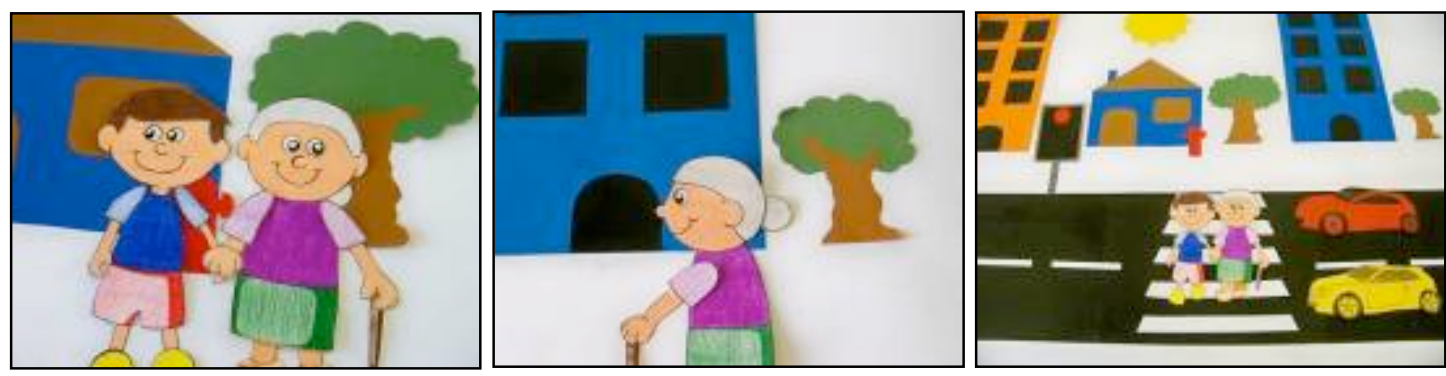

Stop-motion com pessoas

Também conhecida como pixilation, este estilo de animação faz uso de atores reais na captura de movimentos (Figura 08).

Figura 08: Animação com pessoas abordando libras.
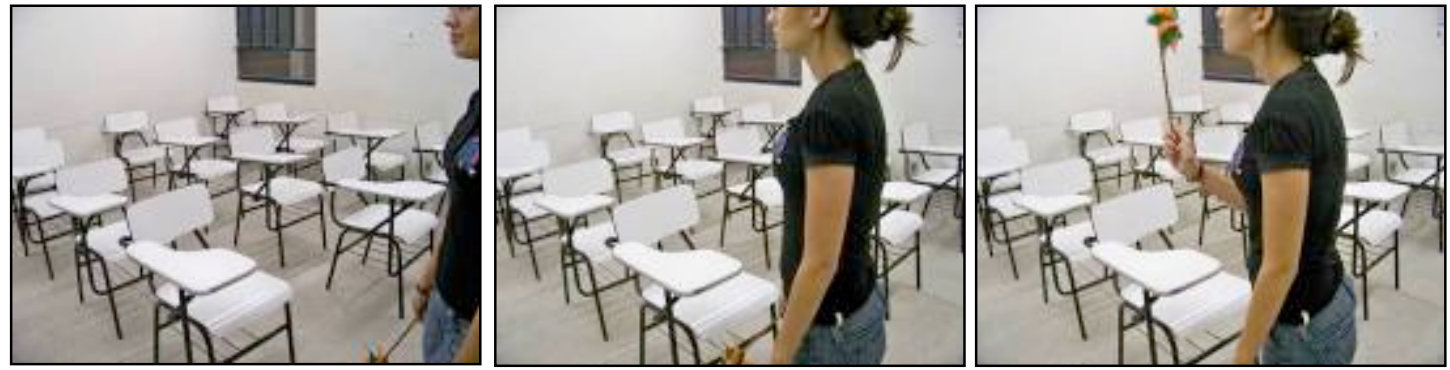

\section{Stop-motion com sombras}

A técnica se utiliza de recortes de papel, com silhuetas bem definidas que, quando postas sobre uma superfície emissora de luz, como um retroprojetor, projeta a sombra do recorte (Figura 09). A captura dos movimentos feitos nestes personagens resulta na animação.

Figura 09: Animação de sombras sobre a cadeia alimentar feita por um aluno.
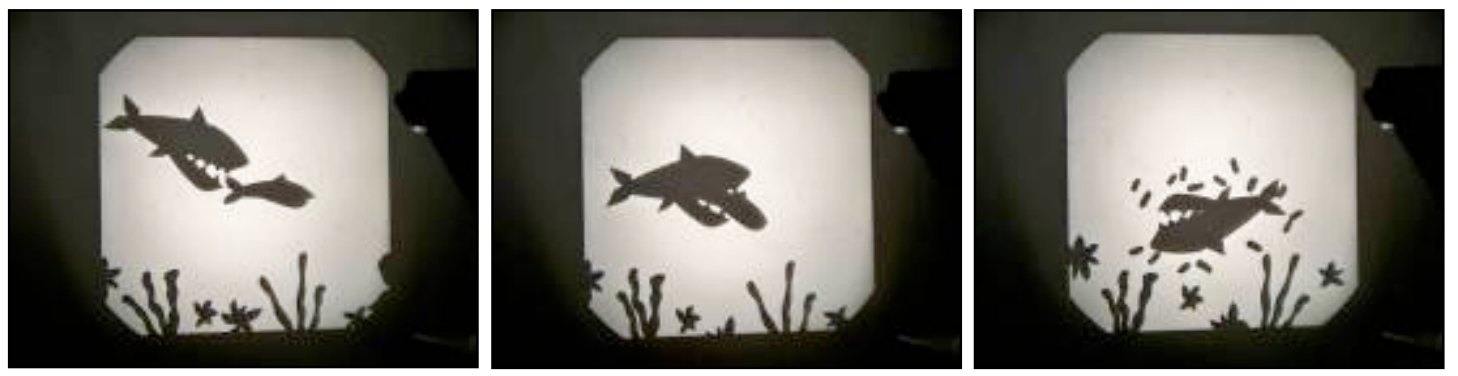

\section{Metodologia Educando com Animação}

O processo de inserção do Design de Animação em escolas requer o percurso por algumas etapas. Estas foram estruturadas e aplicadas com alunos e professores de escolas da rede municipal de ensino da cidade de Caruaru-PE, através do projeto Educando com Animação. Apresentaremos a seguir uma metodologia que visa o emprego das técnicas de animação no processo de ensino e aprendizagem (Figura 10).

Figura 10: Etapas da metodologia para inserção das técnicas de animação em sala de aula. 


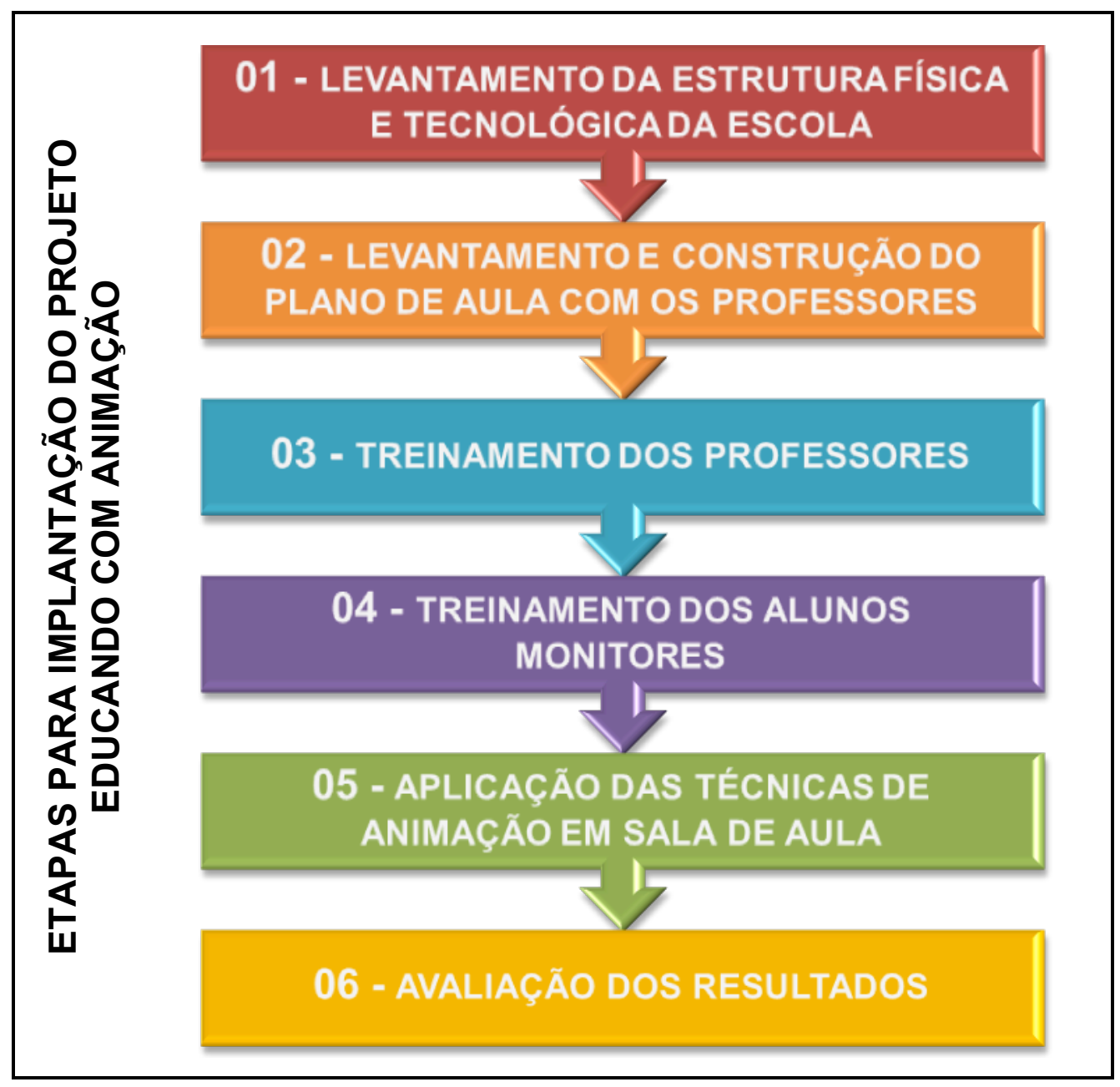

\section{Aplicando a metodologia Educando com Animação em escolas do município de Caruaru-PE}

A partir dos resultados satisfatórios da aplicação do projeto piloto Educando com Animação na escola Municipal Duque de Caxias, nasceu uma parceria com a Prefeitura Municipal de Caruaru, Secretaria de Educação e Secretaria de Cultura, para expandir o projeto para outras escolas do município. Nesse sentido, foram selecionados 20 professores e 40 alunos de 40 escolas municipais: Álvaro Lins, Josélia Florêncio, Kermógenes Dias e Doutor Amaro de Lira e César CAIC.

Apresentaremos nesse artigo a aplicação e avaliação dos resultados obtidos nas disciplinas de Português ( $8^{\mathrm{a}}$ ano), Geografia ( $\left.9^{\circ} \mathrm{Ano}\right)$ e Matemática ( $6^{\circ} \mathrm{Ano}$ ) da Escola Municipal Álvaro Lins, situado no bairro Maurício de Nassau, em Caruaru-PE. Optou-se por trabalhar com turmas de séries e disciplinas diferentes para verificar a eficiência do projeto com crianças de diferentes idades e disciplinas de diferentes conteúdos.

\section{(1) Levantamento da estrutura física e tecnológica da escola}

Nesta etapa foi realizada uma visita técnica para diagnóstico da infraestrutura e dos equipamentos tecnológicos disponíveis na escola. Neste, foi verificado a existência de 01 laboratório do PROINFO com 33 computadores (33 monitores interligados a 16 CPU's), com o sistema operacional Linux - Ubuntu 8.04, internet banda larga, fornecida pelo programa Cidade Conectada da Prefeitura Municipal de Caruaru, um projetor multimídia e um notebook.

\section{(2) Levantamento e construção do plano de aula com os professores}


Nesta etapa foram recolhidos e analisados os planos de aula das disciplinas a fim de compreender como estavam estruturados os seus conteúdos. A partir daí, de forma colaborativa, foram selecionados os conteúdos que melhor se adaptariam ao uso de animação e juntamente com os professores, construídos novos planos de aula.

\section{(3) Treinamento dos professores}

Nesta etapa, os professores foram convidados a participarem de uma capacitação no laboratório de informática do Centro Acadêmico do Agreste da UFPE. Esse treinamento tinha como objetivo apresentar a metodologia Educando com Animação, os princípios básicos e tipos de animação além dos equipamentos e softwares livres que poderiam ser utilizados para a sua produção. A cada novo encontro, uma nova técnica era apresentada e, na sequência, era solicitado dos professores uma aplicação da técnica em um pequeno projeto, que em geral, era realizado em grupos com acompanhamento de monitores.

\section{(4) Treinamento dos alunos monitores}

Nessa etapa, solicitamos aos professores que cada um indicasse dois alunos para serem monitores em suas turmas. Esses alunos, da mesma forma dos professores, foram convidados a vir ao laboratório da UFPE para serem instruídos dos procedimentos para o desenvolvimento de uma animação a partir da aplicação prática das técnicas.

\section{(5) Aplicação das técnicas de animação em sala de aula}

Nesta etapa, a animação foi finalmente levada à escola. Antes do início das atividades em sala de aula, foi realizada uma apresentação a todos os alunos das turmas contempladas pelo projeto para que todos tomassem ciência das atividades que seriam realizadas:

Já em sala aula, as atividades foram estruturadas da seguinte forma: (1) os professores apresentavam parte do conteúdo proposto e dividia a turma em equipes para o desenvolvimento de trabalhos práticos com uso de animação; (2) os grupos eram então conduzidos pelos monitores para o laboratório do PROINFO para iniciarem o processo de desenvolvimento das animações; (3) com o término das animações, essas eram apresentadas e discutidas em sala de aula, com mediação do professor.

\section{(6) Avaliação dos resultados}

Nesta etapa para que pudéssemos avaliar o emprego da metodologia Educando com Animação na escola, utilizamos alguns métodos qualitativos e quantitativos de coleta e análise dos dados, entre eles: Entrevista semiestruturada, questionários, observação e análise comparativa. Os resultados obtidos serão apresentados e analisados na próxima sessão.

\section{Avaliação do projeto Educando com Animação}

Com intuito de obter e comparar os dados referentes a: (1) compreensão dos conteúdos escolares; (2) motivação durante as atividades das disciplinas; (3) uso das TDICs e do laboratório PROINFO nas atividades escolares; (4) desempenho escolar, antes e depois da aplicação do projeto, para tanto dividimos e estruturamos os procedimentos metodológicos em três fases: (a) Antes da aplicação do projeto: (1) entrevistas semiestruturadas e questionários com professores e alunos (b) Durante a aplicação do projeto: (1) análise do processo de desenvolvimento das animações e das discussões geradas pela sua apresentação em sala de aula e (c) Após a aplicação do projeto: (1) entrevistas semiestruturadas com professores e alunos e (2) análise comparativa dos resultados obtidos nas avaliações do período com o desempenho anual e com anos anteriores.

\section{(a) Antes da aplicação do projeto}

Antes da aplicação das entrevistas e questionários, foi encaminhado aos pais e responsáveis pelas crianças um termo de consentimento livre e esclarecido, para que os mesmos pudessem ter conhecimento dos objetivos da pesquisa, dos riscos envolvidos e autorizar ou não a participação dos mesmos. 
O questionário aplicado aos alunos possuía treze questões. Sua finalidade era de gerar um mapeamento do perfil dos sujeitos da pesquisa, compreender de forma objetiva a percepção do aluno quanto às aulas, o seu rendimento e como faziam uso do laboratório de informática. No total 35 alunos foram submetidos ao questionário.

A entrevista aplicada aos alunos possuía onze perguntas. Sua finalidade era compreender os aspectos da rotina das aulas como: dificuldades nas disciplinas, motivação e participação nas aulas e aspectos relacionados ao uso das TIDCs na escola. Foi utilizada uma amostra de cinco alunos por turma, escolhidos de forma aleatória, completando um total de 15 alunos.

O questionário e a entrevista aplicada aos professores antes do projeto continha quinze e onze questões, respectivamente. $O$ objetivo era verificar o perfil destes sujeitos, as estratégias de ensino e aprendizagem e como os mesmos faziam uso de tecnologias digitais dentro e fora da sala de aula. Participaram da pesquisa os 3 professores das disciplinas envolvidas.

\section{(b) Durante a aplicação do projeto}

O desenvolvimento das atividades de animação se deu com acompanhamento das crianças pelos monitores que se utilizavam da observação, da captura de áudio, vídeo e fotografia para coleta e análise das verbalizações e ações durante todo o processo. $O$ objetivo era compreender o processo de construção do conhecimento durante a elaboração da animação, as dificuldades com a metodologia e com a tecnologia envolvida.

\section{(c) Após a aplicação do projeto}

As entrevistas aplicadas com professores e alunos após a execução do projeto continham 8 perguntas cada. O objetivo era compreender a experiência com a metodologia Educando com Animação no que se refere ao: uso de animação em sala de aula como estratégia de ensino e aprendizagem, as contribuições da metodologia para compreensão dos conteúdos das disciplinas, o envolvimento e a motivação, os pontos positivos e negativos da metodologia.

Os resultados obtidos nos permitem observar os seguintes aspectos, quanto a:

\section{(1) Compreensão dos conteúdos escolares}

Os professores e alunos afirmaram ter compreendido de forma clara as etapas necessárias no desenvolvimento das animações. Alguns professores colocaram que a aprendizagem é construída em todas estas etapas, contudo, é no desenvolvimento dos roteiros que se percebe uma maior necessidade de apropriação dos conhecimentos pelos alunos, conforme afirma um docente ao dizer que: "pra eles planejarem o roteiro, eles tinham que ter um conhecimento do assunto [...] e nessa abordagem, eles começaram a buscar mais coisas. Pediram nossa participação, pra falar mais sobre aquele assunto, coisas que na hora que a gente está explicando, eles não pedem". Um aluno reforça: "no projeto, eu participava ativamente, prestava atenção, e com isso, eu acho que eu entendi mais sobre o assunto. Eu acho que entendi mais do que se fosse em livro, caderno, em quadro $[\ldots] "$.

\section{(2) Motivação durante as atividades das disciplinas}

Todos os alunos e professores entrevistados demonstraram uma perceptível aceitação da metodologia Educando com Animação, demonstrando um envolvimento acentuado nas atividades que utilizavam animações. Segundo os professores, a metodologia pode interferir de forma significativa, não só na aprendizagem dos alunos, mas também na motivação dos mesmos nas aulas. Para um dos professores: "os alunos se envolveram com o projeto, participaram mesmo. Foi excelente! Além disso, desenvolveram a parte intelectual". Acerca da metodologia, um aluno afirmou: "o projeto é inovador em sala de aula, é diferente, é divertido e a gente está aprendendo ao mesmo tempo. Então, isso chama a atenção [...] Se toda aula, de toda matéria fosse com animação [...] nossa! A aula seria muito mais interessante, a gente aprenderia muito mais, seria até mais fácil de se aprender".

\section{(3) Uso das TDICS e do laboratório PROINFO nas atividades escolares}

Dentre alguns aspectos importantes do uso das TDICs, podemos destacar a informação de que $100 \%$ dos alunos que responderam os questionários fazem uso do computador em seu dia a dia e 
mais da metade destes possuem computador em seus lares. Contudo, apenas $68 \%$ destes alega utilizar o computador em trabalhos escolares. Há também uma porcentagem significativa de alunos (34\%) que não faz uso do laboratório de informática da escola. Estes dados evidenciam o fato de que as novas tecnologias digitais ainda não se consolidaram como um instrumento educativo para os alunos. Com o projeto $100 \%$ dos alunos passam a incorporar o uso das TDICs e do PROINFO como prática nas suas atividades pedagógicas.

Os professores quando utilizam as TIDCs em sala de aula, ainda fazem de forma superficial, muitas vezes, apenas como projeção de imagens e gráficos através de um projetor multimídia. Em contra partida, os mesmos alunos demonstram um grande interesse e receptividade no uso das TDICs nas estratégias educativas, "A aula fica mais interessante, você fica mais concentrado [...] é uma aula diferente". Quanto a sua participação em sala de aula, os alunos expõem o desejo por uma atuação mais ativa no processo de ensino e aprendizagem.

\section{(4) Desempenho escolar}

Os conteúdos escolares abordados nas animações foram trabalhados também nas avaliações da IV unidade. Com o fechamento das notas do ano letivo, podemos observar que houve uma melhoria no rendimento dos alunos se compararmos a ultima unidade de $2012 \mathrm{com}$ as notas das unidades anteriores (Figura 11) e um aumento na média da avaliação do ano corrente (2012) em relação aos anos anteriores, 2010 e 2011 (Figura 12). Isso revela um indicativo de que a metodologia do projeto interferiu de algum modo na aprendizagem dos discentes.

Figura 11 e 12: (à esq) Médias gerais das notas do $8^{\circ}$ ano da I à IV unidade, do ano letivo de 2012, da disciplina de geografia e (à dir) média geral da nota do $8^{\circ}$ ano da IV unidade, dos anos letivo de 2010 à 2012, da disciplina de geografia.
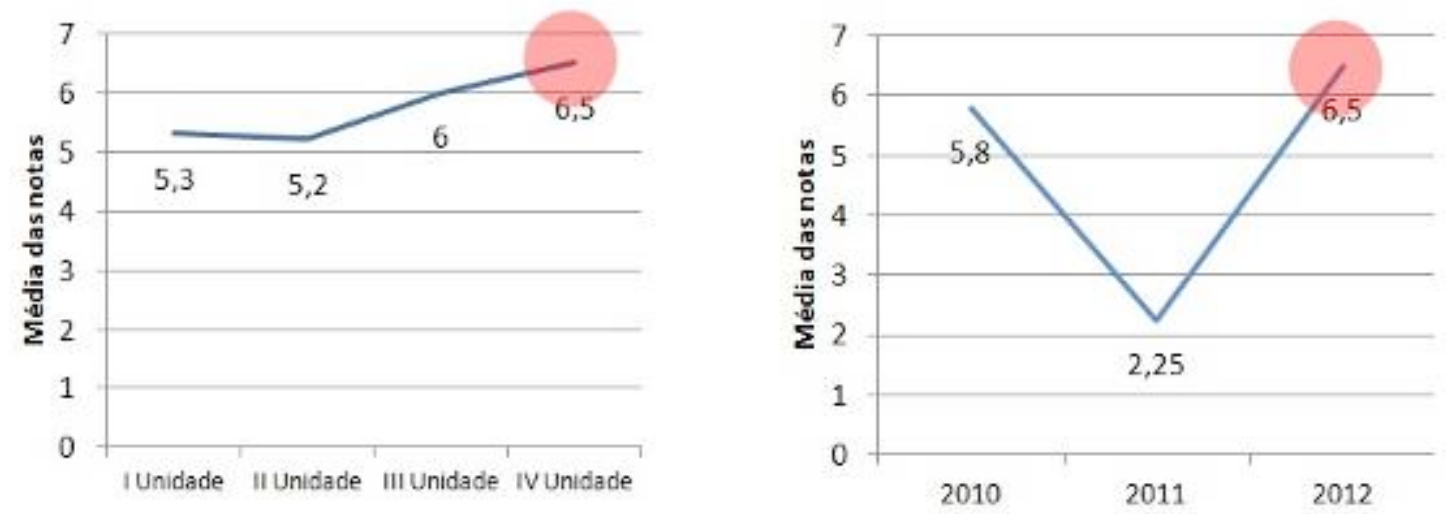

\section{Considerações finais}

"Mudar é difícil, mas é possível" (Freire, 2005: 79). Mudanças são necessárias para que o novo e necessário, como é possível verificar, possa adentrar e fazer parte do cotidiano dos sujeitos. Ideias e métodos retrógrados precisam ser postos de lado, a fim de que novos recursos, disponibilizados pela era da informação, possam ser utilizados massivamente para que as novas demandas sejam acompanhadas e atendidas satisfatoriamente.

A incorporação das técnicas de animação em sala de aula, mais que um modo eficiente de emprego das TDICS, traz novas perspectivas e expectativas ao ambiente de ensino, na medida em que o interesse pelo aprendizado é instigado aos alunos de forma significativa através da motivação que emerge durante todo o processo de elaboração e finalização da animação. A prática da construção do conhecimento, tão anunciada por autores da área de formação educativa, é posta em ação com essa nova ferramenta disponibilizada à escola, intensificando, desta forma, os objetivos almejados pelos docentes, enquanto mediadores do saber. A prática aqui apresentada surge, portanto, como um novo método educacional que aproxima a escola à realidade dos alunos, na medida em que faz uso das linguagens midiáticas já pertencentes ao dia a dia destes. 
É fato, que o trabalho aqui apresentado é ousado e carrega consigo uma proposta de modificação intensa dos métodos de ensino tidos como tradicionais, conferindo às metodologias aplicadas pelos docentes uma nova roupagem, novas possibilidades que fogem do caderno e lousa. Os resultados alcançados constatam que a inclusão digital é necessária a todos da sociedade que se encontram aquém da realidade desejada e necessária para a vivência na sociedade da informação. Tornando-se esta inclusão, cada vez mais, um processo indispensável e promissor na vida de qualquer cidadão, que necessita tratar com intimidade os recursos tecnológicos.

Podemos concluir, então, que o uso da proposta e estratégias do Educando com Design de Animação tem grande potencial para melhoria do atual panorama da educação na escola, tornando o conhecimento mais estimulante, acessível e compreensível para os alunos.

\section{Referências}

ALCOFORADO, M. G.; PADILHA, M. A. S. 2010. Educando com Design de Animação. In: Congresso Brasileiro de Pesquisa e Desenvolvimento em Design, 9, São Paulo, 13 a 16 out. 2010. Anais do $9^{\circ}$ Congresso Brasileiro de Pesquisa e Desenvolvimento em Design. São Paulo: Blucher e Universidade Anhembi Morumbi. p. 2712-2724.

ANDRADE, Daniel. 2007. Animação computadorizada: a imagem em movimento expandida nos meios de comunicação digitais. Tese (Mestrado) - Pontifícia Universidade Católica de São Paulo, São Paulo.

ARAS, V. 2004. Exclusão Digital: o que é isto? Disponível em: <www.suigeneris.pro.br/ excldig.htm>.

BUZATO, Marcelo E. K. 2001. Letramentos digitais e formação de professores. Disponível em: <http://www.educared.org/educa/img_conteudo/marcelobuzato.pdf>.

FILATRO, Andrea. 2007. Design instrucional contextualizado: educação e tecnologia. São Paulo: Senac.

FREIRE, Paulo. 2005. Pedagogia da autonomia: saberes necessários à prática educativa. São Paulo: Terra e Paz.

LÉVY, Pierre. 1999. Cibercultura. Rio de Janeiro: Ed. 34.

\section{Sobre os autores}

Márcio Cleyton Vasconcelos Barbosa, Graduando em Design, UFPE - CAA, bolsista do Programa de Educação Tutorial denominado PET Infoinclusão do MEC/SESu/DIFES. Com atuação na área de Design Instrucional, Design da Informação, Design e Ergonomia, Design e Sustentabilidade e Tecnologias voltadas para a Educação.

<marcio.cleytton@yahoo.com>

Pedro Henrique Gomes dos Santos, Graduando em Design, UFPE - CAA, bolsista do Programa de Educação Tutorial denominado PET Infoinclusão do MEC/SESu/DIFES. Com atuação na área de Design Instrucional e Design do Produto. Possui Trabalhos publicados sobre Design e Educação, Sustentabilidade e Ergodesign.

<pedrophgs@hotmail.com>

Manoel Guedes Alcoforado, Doutorando em Design, UFPE/CAA - UNESP/FAAC, Professor Assistente II do curso de Design da UFPE, Mestre em Design pela UFPE (2007) Especialista em Design da Informação pela UFPE (2002), Graduado em Desenho Industrial pela UFPE (1996), Membro da SBDI e Pesquisador nas áreas de: Design da Informação, Sustentabilidade e Tecnologia de Representação e Prototipagem.

<manoelguedes@hotmail.com> 
Márcio C. Barbosa, Pedro H. dos Santos, Manoel G. Alcoforado, Anna R. Sartore | Educando com design de animação: uma metodologia de ensino e aprendizagem

Anna Rita Sartore, Doutora em Educação, USP, Mestre em Educação pela USP, Especialista em Psicopedagogia Institucional e Clínica, Licenciada em Ciências Físicas e Biológicas e em

Pedagogia, Professora Adjunta da UFPE, Coordenadora Geral do Programa de Educação Tutorial, MEC/SESu/DIFES, de Infoinclusão. Com atuação na área da Educação, com ênfase na formação de Professores, Tecnologias, Ciências e Relação entre Psicanálise e Educação.

<ar.sartore@uol.com.br>

[Artigo recebido em dezembro de 2012, aprovado em dezembro de 2012] 